\title{
Carotenoids are more bioavailable from papaya than from tomato and carrot in humans: a randomised cross-over study
}

\author{
Ralf M. Schweiggert ${ }^{1,2 *}$, Rachel E. Kopec ${ }^{2,3}$, Maria G. Villalobos-Gutierrez ${ }^{4}$, Josef Högel ${ }^{5}$, \\ Silvia Quesada ${ }^{6}$, Patricia Esquivel ${ }^{4}$, Steven J. Schwartz ${ }^{2,3}$ and Reinhold Carle ${ }^{1}$ \\ ${ }^{1}$ Institute of Food Science and Biotechnology, Hohenheim University, Stuttgart, Germany \\ ${ }^{2}$ Department of Food Science and Technology, The Obio State University, Columbus, OH, USA \\ ${ }^{3}$ Department of Human Nutrition, The Obio State University, Columbus, OH, USA \\ ${ }^{4}$ School of Food Technology, Universidad de Costa Rica, San José, Costa Rica \\ ${ }^{5}$ Institute of Human Genetics, Ulm University, Ulm, Germany \\ ${ }^{6}$ Department of Biochemistry, School of Medicine, Universidad de Costa Rica, San José, Costa Rica
}

(Submitted 6 March 2013 - Final revision received 10 July 2013 - Accepted 10 July 2013 - First published online 12 August 2013)

\begin{abstract}
Carrot, tomato and papaya represent important dietary sources of $\beta$-carotene and lycopene. The main objective of the present study was to compare the bioavailability of carotenoids from these food sources in healthy human subjects. A total of sixteen participants were recruited for a randomised cross-over study. Test meals containing raw carrots, tomatoes and papayas were adjusted to deliver an equal amount of $\beta$-carotene and lycopene. For the evaluation of bioavailability, TAG-rich lipoprotein (TRL) fractions containing newly absorbed carotenoids were analysed over $9.5 \mathrm{~h}$ after test meal consumption. The bioavailability of $\beta$-carotene from papayas was approximately three times higher than that from carrots and tomatoes, whereas differences in the bioavailability of $\beta$-carotene from carrots and tomatoes were insignificant. Retinyl esters appeared in the TRL fractions at a significantly higher concentration after the consumption of the papaya test meal. Similarly, lycopene was approximately 2.6 times more bioavailable from papayas than from tomatoes. Furthermore, the bioavailability of $\beta$-cryptoxanthin from papayas was shown to be 2.9 and 2.3 times higher than that of the other papaya carotenoids $\beta$-carotene and lycopene, respectively. The morphology of chromoplasts and the physical deposition form of carotenoids were hypothesised to play a major role in the differences observed in the bioavailability of carotenoids from the foods investigated. Particularly, the liquid-crystalline deposition of $\beta$-carotene and the storage of lycopene in very small crystalloids in papayas were found to be associated with their high bioavailability. In conclusion, papaya was shown to provide highly bioavailable $\beta$-carotene, $\beta$-cryptoxanthin and lycopene and may represent a readily available dietary source of provitamin A for reducing the incidence of vitamin A deficiencies in many subtropical and tropical developing countries.
\end{abstract}

Key words: $\beta$-Carotene: Lycopene: $\beta$-Cryptoxanthin: Bioavailability

Many fruits and vegetables contain highly bioactive carotenoids of utmost interest for maintaining human health. For instance, the vitamin A precursor $\beta$-carotene represents an important nutritional source of vitamin $\mathrm{A}$ in the human diet. Vitamin A deficiency is a major nutritional issue in many developing countries, particularly affecting infants, young children and pregnant women due to its role in immune function and growth ${ }^{(1)}$. Carotenoids such as lycopene are not converted to vitamin A, but they may still have health-promoting properties. For example, the consumption of lycopene-rich foods has been reported to be inversely associated with the incidence of CVD and cancer ${ }^{(2)}$.
The bioactivity of carotenoids requires the preceding release from the food matrix and subsequent absorption. However, the bioavailability of carotenoids is not yet fully understood due to the large variety of factors that influence this process, which has been reviewed in detail previously $^{(3-5)}$. For instance, the basic chemical structure of a carotenoid has a direct impact on its bioavailability. Van het Hof et al. ${ }^{(6)}$ reported a 5-fold higher bioavailability of lutein than of $\beta$-carotene from a mixed-vegetable diet. Kostic et $a l .{ }^{(7)}$ had previously demonstrated a similar trend after consumption of equimolar doses of lutein and $\beta$-carotene dissolved in oil in their study participants. Moreover, the effects

Abbreviations: GI, gastrointestinal; PDA, photodiode array; TRL, TAG-rich lipoprotein.

* Corresponding author: R. M. Schweiggert, email ralf.schweiggert@uni-hohenheim.de 
of the interactions between different carotenoids and the total carotenoid dose on bioavailability have been discussed previously, as carotenoids may compete for absorption ${ }^{(8,9)}$. For example, the co-consumption of lutein had a negative effect on the absorption of $\beta$-carotene and vice versa in many participants of Kostic et al.'s study ${ }^{(7)}$.

The effects of the co-consumption of carotenoids with meal lipids $^{(10)}$ and dietary fibres ${ }^{(11,12)}$ have also been studied. However, the initial physical state of the carotenoid in the plant cell is an often-overlooked factor that may play a role in the release and subsequent absorption of carotenoids. In plants, carotenoids are deposited in different types of plastids, such as chloroplasts and chromoplasts ${ }^{(13)}$. The low bioavailability of carotenoids from raw green vegetables has been explained by their complexation in protein-pigment complexes of the photosystems located in chloroplasts. Being of utmost importance for photosynthesis in plants, $\beta$-carotene is present in the reaction centre complexes, whereas the majority of carotenoids, particularly xanthophylls, can be found in the light-harvesting antenna complexes ${ }^{(14)}$. Thermal food treatment leads to the release of carotenoids from these complexes and ultimately results in enhanced bioavailability ${ }^{(15)}$. In yellow, orange and red fruits and vegetables, the morphology of chromoplasts has been hypothesised to have a major impact on the bioavailability of carotenoids. Carrot root cells contain comparatively large, crystalline aggregations of $\beta$-carotene, whereas nanoscale substructures of lipid-dissolved and liquidcrystalline $\beta$-carotene can be found in papaya fruits. At the same time, crystalloid accumulations of lycopene have been identified in both papayas and tomatoes. However, the size of the lycopene crystals is significantly smaller in papayas than in tomatoes ${ }^{(13,16)}$.

Although other factors may also essentially influence the release of carotenoids from papayas, carrots and tomatoes, the above-mentioned microscopic observations have led our group to carry out a series of in vitro digestion experiments, in which an enhanced release of lycopene and $\beta$-carotene from papayas than from carrots and tomatoes has been demonstrated $^{(17)}$. In order to verify the results of our in vitro study, we sought to make the same comparison in healthy human subjects in the present study. The bioavailability of lycopene from papayas $v$. tomatoes was compared. Since all the three fruits contain $\beta$-carotene, a three-way cross-over clinical trial was designed to evaluate the bioavailability of this important vitamin A precursor. Moreover, papaya fruits contain high amounts of $\beta$-cryptoxanthin ${ }^{(18)}$, a provitamin A carotenoid whose bioavailability from foods is rarely evaluated. Thus, the bioavailability of $\beta$-cryptoxanthin was also assessed.

\section{Subjects and methods \\ Participants}

A total of sixteen healthy, non-pregnant, non-smoking men and women aged 21-44 years (median 27 years) were enrolled after checking eligibility, which was based on a health and lifestyle questionnaire. Women were, on average,
$25.9($ SEM 2.6$)$ years old with a BMI of $22.4(\operatorname{sem~} 3.7) \mathrm{kg} / \mathrm{m}^{2}$, while men were 28.7 (SEM 7.7) years old with a BMI of 25.6 (SEM $2 \cdot 1) \mathrm{kg} / \mathrm{m}^{2}$. Exclusion criteria included any history of chronic gastrointestinal disease, use of medications affecting lipid metabolism, regular use of carotenoid-containing supplements and frequent alcohol consumption. Since the study was conducted at the University of Costa Rica (San Jose, Costa Rica), all the subjects were of Hispanic ethnicity. Signed informed consent was obtained. The present study was conducted according to the guidelines laid down in the Declaration of Helsinki, and all procedures involving human subjects were approved by both the Comité Ético Científico of the Universidad de Costa Rica (registry no. VI-3404-2011) and the Biomedical Sciences Institutional Review Board of The Ohio State University (protocol no. 2011H0336). The study was registered at clinicaltrials.gov (NCT no. NCT01748916).

\section{Test meals}

Carrots (Daucus carota L. ssp. sativus (Hoffm.) Schübl et G. Martens), tomatoes (Solanum lycopersicum L.) and red-fleshed papaya fruits (Carica papaya L. var. Pococî) were obtained from a local supermarket in Costa Rica. Before each clinical day, the actual lycopene and $\beta$-carotene contents of the test foods were determined using a HPLC photodiode array (PDA) detector as described below. The dose of lycopene delivered each day was set to $13.0 \mathrm{mg}$. Thus, the volume of tomatoes and papayas fed was adjusted to deliver the same lycopene dose $(13.0 \mathrm{mg})$. Furthermore, the amount of carrots fed was chosen to dose-match $\beta$-carotene present in the fixed amount of papayas. Due to the natural inhomogeneity of the carotenoid content of the used plant foods, the sizes of the test meals were varied slightly from one clinical day to another (papaya 400-506 g, tomato 256-396g and carrot 25-35g). Papayas, tomatoes and carrots were used raw after washing, peeling (only papayas) and cutting into equally small pieces (about $1.5 \mathrm{~cm} \times 1.5 \mathrm{~cm} \times 1.5 \mathrm{~cm}$ ). Along with the carotenoid test food, $150 \mathrm{~g}$ of a low-fat yogurt enriched with soya oil to a total lipid content of $10 \%(\mathrm{w} / \mathrm{w})$ and two slices $(45 \mathrm{~g})$ of fatfree white bread were part of the test meals.

\section{Experimental design}

All the participants ( $n$ 16) of the present three-way cross-over study visited the clinic on four different occasions from August 2011 through September 2011. On the first visit, the clinical procedures were explained to the participants in detail, and their age and BMI $\left(\mathrm{kg} / \mathrm{m}^{2}\right)$ were recorded. The participants were instructed to refrain from consuming foods rich in lycopene, $\beta$-carotene and $\beta$-cryptoxanthin 2 weeks before their second, third and fourth clinical visits. Foods to be avoided were selected according to the USDA-Nutrition Coordinating Center and National Cancer Institute Nutrient Database ${ }^{(19)}$ and publications on local fruits. Commonly consumed Costa Rican foods with contents higher than about $0 \cdot 1 \mathrm{mg}$ $\beta$-carotene/lycopene/ $\beta$-cryptoxanthin per $100 \mathrm{~g}$ of fresh 
weight were added to the list. A list containing these foods and many local carotenoid-rich fruits and vegetables, such as sapote (Pouteria sapota) and guava (Psidium guajava L.), was provided.

Following a randomised cross-over design, each participant consumed the papaya, tomato or carrot test meal once. The order on which clinical visit the participants consumed the test meals (papaya test meal: P; tomato test meal: $\mathrm{T}$; carrot test meal: C) was randomised. The test meal order PTC, TCP, CTP and CPT was followed by three randomly selected participants each (twelve participants), whereas the test meal order PCT and TPC was followed by only two participants each (sixteen participants in total). In the latter two groups, two participants could not schedule another day for the clinical visit. The participants fasted overnight for $12 \mathrm{~h}$ before visiting the School of Medicine (University of Costa Rica). After the collection of a baseline blood sample, the participants consumed the test meals under supervision within $20 \mathrm{~min}$. The participants were instructed to chew at least fifteen times per bite. After the consumption of the test meal $(0 \mathrm{~h})$, further blood samples were collected consecutively at $2,3,4,5,6,8$ and $9 \cdot 5 \mathrm{~h}$. At $4.5 \mathrm{~h}$, a standardised lunch low in carotenoids (approximately $140 \mathrm{~g}$ of rice, $120 \mathrm{~g}$ of beans and $95 \mathrm{~g}$ of beef) was consumed by the participants, providing $2.93 \mathrm{MJ}$ energy from $30.5 \mathrm{~g}$ fat, $33.4 \mathrm{~g}$ protein and $88.0 \mathrm{~g}$ carbohydrates. The participants consumed water ad libitum, whereas they were not allowed to consume other foods and beverages during the clinical stay. No harms or adverse effects were observed during the study.

\section{Blood sampling and analysis}

Blood samples $(10 \mathrm{ml})$ were drawn from a forearm vein into $\mathrm{K}_{2}$ EDTA tubes (EDTA/K2-Gel Monovette; Sarstedt) and centrifuged at $1700 \mathrm{~g}$ for $10 \mathrm{~min}$ at $4^{\circ} \mathrm{C}$ (Centrifuge 5810R; Eppendorf) for plasma separation. Plasma samples were kept at $4^{\circ} \mathrm{C}$ for up to $1 \mathrm{~h}$ during transport, and TAG-rich lipoprotein (TRL) fractions were subsequently isolated following a slightly modified method published previously ${ }^{(20,21)}$. Briefly, $2.5 \mathrm{ml}$ of plasma were transferred into thin-wall polyallomer tubes that were preconditioned with a $5 \%(\mathrm{w} / \mathrm{v})$ polyvinyl alcohol solution. The plasma was carefully mixed with $0.8 \mathrm{~g}$ of $\mathrm{KBr}$ and subsequently overlayered with $1 \mathrm{ml} \mathrm{NaCl}$ solution (density $1.006 \mathrm{~kg} / \mathrm{l}$ ). After ultracentrifugation (WX Ultra 80; Thermo Fisher Scientific) for $30 \mathrm{~min}$ at $155000 \mathrm{~g}$ in a swinging bucket rotor SW501 (Beckman Coulter), the tubes were punctured at a fixed position and $0.5 \mathrm{ml}$ of the TRL-containing supernatant were removed. Rinsing the tube once with $0.25 \mathrm{ml}$ of the above-mentioned $\mathrm{NaCl}$ solution yielded the TRL fraction $(0.75 \mathrm{ml})$, which was stored at $-80^{\circ} \mathrm{C}$ until further analysis. Before the carotenoid analysis, TRL samples were made up to a final volume of $1.0 \mathrm{ml}$ with a saline solution $(0.9 \%(\mathrm{w} / \mathrm{v})$ aqueous $\mathrm{NaCl})$.

\section{Analysis of carotenoids in the test meals}

All procedures were carried out using amber glassware or Al-covered containers at the University of Costa Rica. The carotenoids present in the test foods were extracted following a modified method published by Schweiggert et al. ${ }^{(22)}$. Papaya fruits and carrots used for test meal preparation were halved, and representative samples were taken and pooled. For the analysis of carotenoids in tomatoes, at least five randomly selected fruits of each lot were analysed. Subsequently, a $10 \cdot 0$ (SEM $0 \cdot 1) \mathrm{g}$ aliquot of the freshly homogenised food sample was blended with $0.5 \mathrm{~g} \mathrm{CaCO}_{3}, 0.5 \mathrm{~g}$ Celite $^{\circledR} 545$ and $25 \mathrm{ml}$ of a mixture (1:1:1, by vol.) of methanol, ethyl acetate and light petroleum (boiling point $40-60^{\circ} \mathrm{C}$ ) containing $0 \cdot 1 \mathrm{~g} / 1$ of butylated hydroxytoluene and $0.1 \mathrm{~g} / \mathrm{l}$ of butylated hydroxyanisole. After filtration, the extraction of the recovered solids was repeated thrice with $25 \mathrm{ml}$ of the above-mentioned extraction mixture. After mixing the filtrates, the organic phase was removed and washed with deionised water and evaporated to dryness at room temperature under reduced pressure. The dry residue was redissolved in $100 \mathrm{ml}$ of light petroleum and saponified using $100 \mathrm{ml}$ of a methanolic $30 \%(\mathrm{w} / \mathrm{v})$ $\mathrm{KOH}$ solution for $3 \mathrm{~h}$. The saponified extracts were transferred into a separatory funnel, and the upper fraction was separated and washed twice with deionised water. The upper fraction was dried with approximately $5 \mathrm{~g} \mathrm{Na}_{2} \mathrm{SO}_{4}$ and evaporated to dryness under reduced pressure at $25^{\circ} \mathrm{C}$. The remaining residue was dissolved in $2 \mathrm{ml}$ of dichloromethane and subsequently made up to $10 \mathrm{ml}$ using acetonitrile. The samples were analysed by HPLC within $\leq 30 \mathrm{~min}$ after being re-dissolved in the solvent. For the HPLC analysis, a MerckHitachi HPLC system (Merck) equipped with an analytical Sunfire C18-column $(250 \times 4.6 \mathrm{~mm}$ inner diameter $)$ with a particle size of $5 \mu \mathrm{m}$ was used. An isocratic elution method using acetonitrile and dichloromethane (80:20, v/v) with a total run time of $15 \mathrm{~min}$ at a flow rate of $1 \mathrm{ml} / \mathrm{min}$ was used. The column temperature was set to $30^{\circ} \mathrm{C}$. Carotenoids were monitored at $450 \mathrm{~nm}$ (L-7100 UV-Vis Detector; Merck), and the injection volume was $10 \mu \mathrm{l}$. The identification of $\beta$-carotene and lycopene was done by comparing their UV/Vis absorption spectra and retention times with those of authentic standards (Sigma Aldrich). External calibration curves of lycopene and $\beta$-carotene were used for quantification.

The analysis of $\alpha$-carotene in carrots and $\beta$-cryptoxanthin esters in papaya fruits was performed at The Ohio State University after shipping the samples on dry ice. The extraction method described above was used. The HPLC-MS system used for identification and quantification is described below (see the 'Analysis of carotenoids in TAG-rich lipoprotein samples' section). Authentic standards of $\alpha$-carotene and $\beta$-cryptoxanthin (Chromadex Irvine) were used for identification and quantification. Since no $\beta$-cryptoxanthin ester standards were available, esters were identified by UV/Vis and mass spectra published by Schweiggert et al. ${ }^{(18)}$ and quantified by a PDA using free $\beta$-cryptoxanthin.

\section{Analysis of carotenoids in TAG-rich lipoprotein samples}

After shipping the TRL samples from the University of Costa Rica to The Ohio State University on dry ice within $1 \mathrm{~d}$, TRL carotenoid analysis was carried out at the Department of Food Science (The Ohio State University, Columbus, $\mathrm{OH}$, 
USA). The carotenoid extraction procedure and HPLCPDA-MS/MS analysis have been described in detail previously ${ }^{(23)}$. The identification of carotenoids was done by comparing their UV/Vis absorption spectra, retention times and parent-daughter mass transitions with those of authentic standards. $\beta$-Cryptoxanthin esters and lycopene $(Z)$-isomers were identified by their UV/Vis absorption and mass spectra as described earlier ${ }^{(18)}$. Linear calibration curves of $\beta$-carotene, $\alpha$-carotene, $\beta$-cryptoxanthin, lycopene and retinyl palmitate (Sigma Aldrich Chemie $\mathrm{GmbH}$ ) were used for quantification with a HPLC-PDA. In addition to the HPLC-PDA, HPLC-MS/ MS was used for the quantification of the concentrations of (all-E)- $\beta$-carotene, and the concentrations of retinyl esters were determined using HPLC-MS/MS as described by Kopec et al. ${ }^{(23)}$. Total lycopene represents the sum of (all-E)lycopene and the $(Z)$-isomers. The concentrations of the stock solutions were determined spectrophotometrically using their corresponding absorption coefficients, after dissolution in the respective solvent ${ }^{(24)}$.

\section{Statistical analyses of absorption efficiency}

The baseline-corrected area under the concentration $v$. time curve (AUC) over $9.5 \mathrm{~h}$ was calculated from the corresponding concentration/time data points by trapezoidal approximation using Excel 2010 (Microsoft Corporation). The AUC was used as a representative parameter for postprandial absorption efficiency as described previously ${ }^{(25)}$. Statistical analyses were performed using SAS 9.1 (SAS Institute, Inc.). The normality and homogeneity of variance were verified using Kolmogorov-Smirnov and Levene's tests $(P<0.05)$. Since single data series were not normally distributed, the non-parametrical Cochran-Mantel-Haenszel test with the different food sequences as strata was used for the overall and pairwise identification of significant differences between means, controlling for carry-over, period and time effects. Additionally, an ANOVA was carried out, modelling carotenoid absorption with a linear mixed model using the covariates carotenoid food source (papaya, tomato and carrot), food sequence (six combinations), period (three clinical visits) and participants ( $n$ 16). The participant was implemented as a hierarchical subordinate of the sequence. Results are expressed as means with their standard errors, unless otherwise stated.

\section{Results}

\section{Participants and test meals}

The characteristics of the sixteen participants have been described above. The amounts of carotenoids in the test meals are presented in Table 1 . Both the papaya and tomato test meals were adjusted to deliver $13.0 \mathrm{mg}$ lycopene every clinical day. The papaya test meal contained approximately $1.3 \mathrm{mg} \beta$-carotene, whereas the carrot test meal contained approximately $1.6 \mathrm{mg} \beta$-carotene. As described above, the $\beta$-carotene dose of the tomato test meal $(2.3 \mathrm{mg})$ could not be adjusted, since lycopene $(13.0 \mathrm{mg}$ ) was used for calculating the necessary test meal amount. The papaya test meal additionally contained about $2 \cdot 1 \mathrm{mg}$ of total $\beta$-cryptoxanthin.

\section{Carotenoid and retinyl ester responses in TAG-rich lipoprotein fractions}

AUC values for all the carotenoids and retinyl esters are summarised in Table 2. On comparing the carotenoid response of total lycopene in the papaya test meal $v$. tomato test meal (Fig. 1(a)), a significantly larger AUC was observed when the papaya test meal was consumed $(P \leq 0 \cdot 001)$. The mean $\mathrm{AUC}_{\text {lycopene }}$ after the consumption of the papaya test meal was $2 \cdot 6$-fold greater than that after the consumption of the tomato test meal.

Since carrots, tomatoes and papayas all contain $\beta$-carotene, a three-way comparison was carried out. The $\beta$-carotene doses ingested by the participants were nearly matched for the papaya (approximately $1.3 \mathrm{mg}$ ) and carrot (approximately $1.6 \mathrm{mg}$ ) test meals, whereas the tomato test meal contained a

Table 1. Carotenoid levels and retinol activity equivalents (RAE) of the test meals (Mean values and standard deviations)

\begin{tabular}{|c|c|c|c|c|c|c|}
\hline & \multicolumn{6}{|c|}{ Carotenoid dose in the corresponding test meal $(\mathrm{mg})$} \\
\hline & \multicolumn{2}{|c|}{ Papaya } & \multicolumn{2}{|c|}{ Carrot } & \multicolumn{2}{|c|}{ Tomato } \\
\hline & Mean & SD & Mean & SD & Mean & SD \\
\hline$\alpha$-Carotene & \multicolumn{2}{|c|}{ NA } & 0.74 & 0.08 & \multicolumn{2}{|c|}{ NA } \\
\hline$\beta$-Carotene & $1 \cdot 28^{\star}$ & 0.16 & $1.60^{*}$ & 0.01 & $2 \cdot 25$ & 0.82 \\
\hline Total lycopene & $13 \cdot 00^{*}$ & 0.01 & \multicolumn{2}{|c|}{ ND } & $13 \cdot 00^{*}$ & 0.01 \\
\hline$\beta$-Cryptoxanthin & 0.61 & 0.10 & \multicolumn{2}{|c|}{ ND } & \multicolumn{2}{|c|}{ ND } \\
\hline$\beta$-Cryptoxanthin laurate & 0.50 & 0.16 & \multicolumn{2}{|c|}{ ND } & \multicolumn{2}{|c|}{ ND } \\
\hline$\beta$-Cryptoxanthin caprate & 1.55 & 0.38 & \multicolumn{2}{|c|}{ ND } & \multicolumn{2}{|c|}{ ND } \\
\hline$\beta$-Cryptoxanthin myristate & 0.21 & 0.04 & \multicolumn{2}{|c|}{ ND } & \multicolumn{2}{|c|}{ ND } \\
\hline Total $\beta$-cryptoxanthin $\dagger$ & $2 \cdot 11$ & 0.74 & \multicolumn{2}{|c|}{ ND } & \multicolumn{2}{|c|}{ ND } \\
\hline RAE $\ddagger$ & 0.19 & 0.04 & 0.16 & 0.01 & 0.19 & 0.07 \\
\hline
\end{tabular}

NA, not available; ND, not detected.

${ }^{*} \beta$-Carotene and lycopene doses were matched by adjusting the amount of carrots and tomatoes, respectively.

$\dagger$ Total $\beta$-cryptoxanthin dose without the weight of the fatty acid moieties of the $\beta$-cryptoxanthin esters.

$\ddagger \mathrm{RAE}$ were calculated as follows: $1 \mu \mathrm{g} \mathrm{RAE}=12 \mu \mathrm{g} \beta$-carotene and $24 \mu \mathrm{g}$ other provitamin A carotenoids, i.e. $\beta$-cryptoxanthin ${ }^{(33)}$. 
Table 2. AUC levels $(\mathrm{nmol} \times \mathrm{h} / \mathrm{l})$ for the carotenoids and retinyl esters (vitamin $\mathrm{A}$ ) after test meal consumption (Medians and 25th-75th percentiles)

\begin{tabular}{|c|c|c|c|c|c|c|c|c|c|c|}
\hline \multirow[b]{2}{*}{ Test meals } & \multicolumn{2}{|c|}{$\beta$-Carotene } & \multicolumn{2}{|c|}{ Lycopene } & \multicolumn{2}{|c|}{$\beta$-Cryptoxanthin } & \multicolumn{2}{|c|}{$\alpha$-Carotene } & \multicolumn{2}{|c|}{ Retinyl esters } \\
\hline & Median & $\begin{array}{l}\text { 25th-75th } \\
\text { percentile }\end{array}$ & Median & $\begin{array}{l}\text { 25th-75th } \\
\text { percentile }\end{array}$ & Median & $\begin{array}{l}\text { 25th-75th } \\
\text { percentile }\end{array}$ & Median & $\begin{array}{l}\text { 25th-75th } \\
\text { percentile }\end{array}$ & Median & $\begin{array}{l}\text { 25th-75th } \\
\text { percentile }\end{array}$ \\
\hline Papaya & 163 & $155-210$ & 174 & $130-249$ & 605 & $404-704$ & ND & & 284 & $210-375$ \\
\hline Tomato & 62 & $28-103$ & 58 & $47-102$ & ND & & ND & & 99 & $56-190$ \\
\hline Carrot & 64 & $40-96$ & ND & & ND & & 31 & $26-38$ & 106 & $60-251$ \\
\hline
\end{tabular}

ND, not determined.

slightly higher dose of $\beta$-carotene (approximately $2.3 \mathrm{mg}$ ). Nevertheless, carotenoid absorption was significantly $(P \leq 0.001)$ higher after the consumption of the papaya test meal, resulting in 2.9- and 3.1-fold higher AUC for the papaya test meal than for the carrot and tomato test meals, respectively. In contrast, differences between $\beta$-carotene absorption for the tomato and carrot test meals were not statistically significant $(P>0 \cdot 863)$, as shown in Fig. 1(b).

Furthermore, carotenoids absorbed from single test meal types were compared with each other. Notably, although the $\beta$-cryptoxanthin dose (approximately $2 \cdot 1 \mathrm{mg}$ ) was significantly lower than the lycopene dose $(13.0 \mathrm{mg})$, greater absorption of $\beta$-cryptoxanthin was observed after the ingestion of the papaya test meal. The average AUC for $\beta$-cryptoxanthin was $2 \cdot 9$ - and $2 \cdot 3$-fold higher than that for $\beta$-carotene and lycopene for the papaya test meal, respectively $(P \leq 0 \cdot 001)$. Furthermore, the average peak concentration of $\beta$-cryptoxanthin at $6 \mathrm{~h}$ was approximately 3.9- and 3.2-fold higher than that of $\beta$-carotene and lycopene, respectively (Fig. 2(a)). By applying a HPLC-MS/MS method the same as that used for the identification of $\beta$-cryptoxanthin esters in papayas, we were unable to detect $\beta$-cryptoxanthin esters in the selected $6 \mathrm{~h}$ TRL fractions when the participants consumed the papaya test meal.

In the carrot test meal, the AUC for $\beta$-carotene was 1.8 times higher than that for $\alpha$-carotene (Fig. 2(b)), which is reflective of the ratio of these carotenoids in the test meal ( $\beta$-carotene dose: $\alpha$-carotene dose, $2 \cdot 1$ ).

The provitamin A carotenoids $\beta$-carotene and $\beta$-cryptoxanthin can be converted into retinyl esters in the intestinal enterocyte and packaged into chylomicrons (present in the TRL fractions). Thus, the concentrations of postprandial retinyl esters in the TRL fractions were also measured (shown in Fig. 1(c)). After the consumption of the papaya test meal, the AUC for retinyl esters was 2.0- and 2.6-fold higher than those after the consumption of the carrot and tomato test meals, respectively. Irrespective of the test meal consumed, the major retinyl ester was identified as retinyl palmitate (approximately $73 \%$ of total retinyl esters). The absorption peaks appeared to coincide with the peak in the $\beta$-carotene absorption curve, similarly resulting in highest concentrations at $6 \mathrm{~h}$ (Fig. 1(c)).

Baseline-corrected maximum carotenoid concentrations of $35 \cdot 2$ (SEM 7.7) and 17.5 (SEM 4.2) nmol/1 plasma for lycopene were reached in the TRL fractions $5-6 \mathrm{~h}$ after the consumption of the papaya and tomato test meals, respectively. Accordingly, 29.1 (SEM 6.0), 8.8 (SEM 1.8) and 11.6 (SEM 2.0) nmol/1 plasma were found as the average $\beta$-carotene peak concentrations 5-6h after the consumption of the papaya, carrot and tomato test meals, respectively (Fig. 1(b)). The highest average retinyl ester concentrations (49.4 (sem 11.4) nmol/l) were reached on consumption of the papaya test meal (Fig. 1(c)). The highest average $\beta$-cryptoxanthin concentration of $112 \cdot 0($ SEM $17 \cdot 2) \mathrm{nmol} / 1$ plasma was measured $6 \mathrm{~h}$
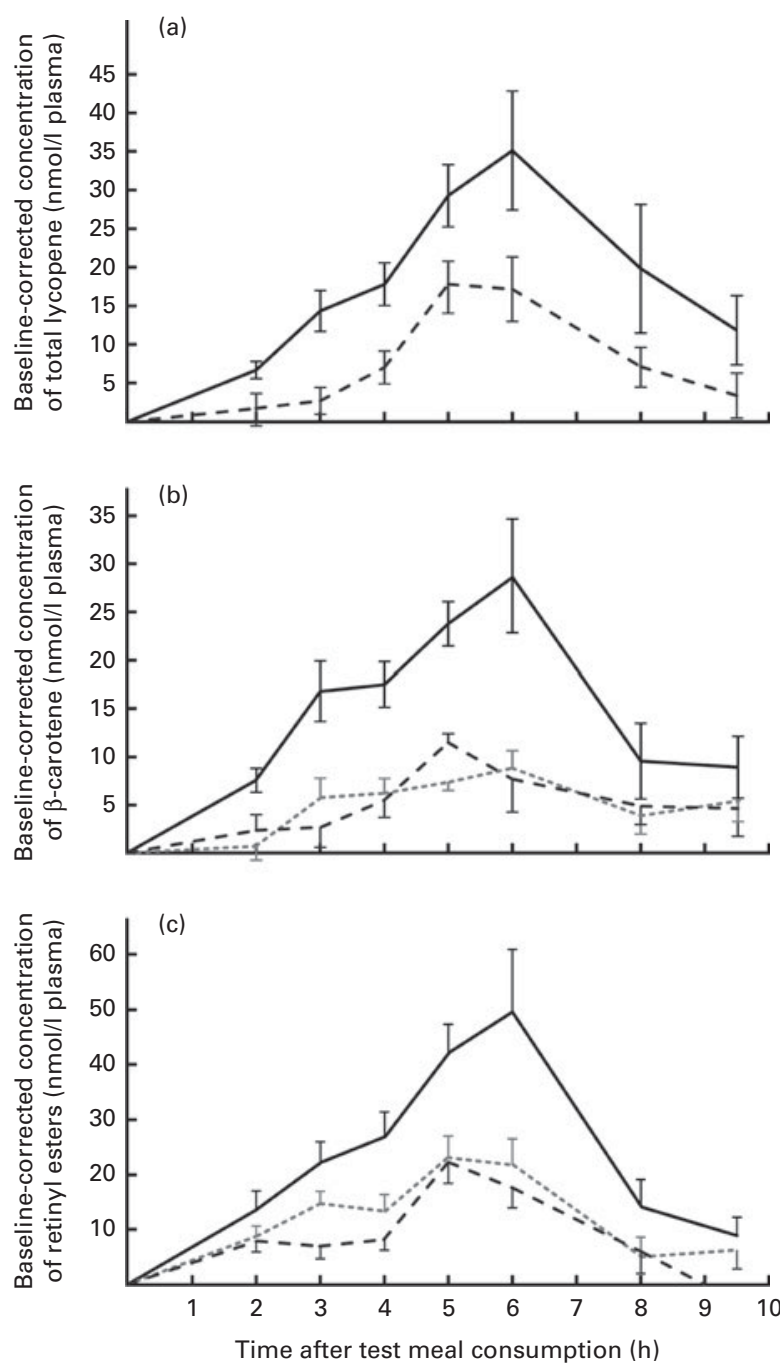

Fig. 1. Baseline-corrected plasma TAG-rich lipoprotein concentrations of (a) total lycopene, (b) $\beta$-carotene and (c) retinyl esters over $9.5 \mathrm{~h}$ after the consumption of the test meals. Values are means $(n$ 16), with their standard errors represented by vertical bars. Mean value of the papaya test meal (-) was significantly higher than that of the carrot (...) or tomato (--) test meal $(P \leq 0.001)$. 
(a)

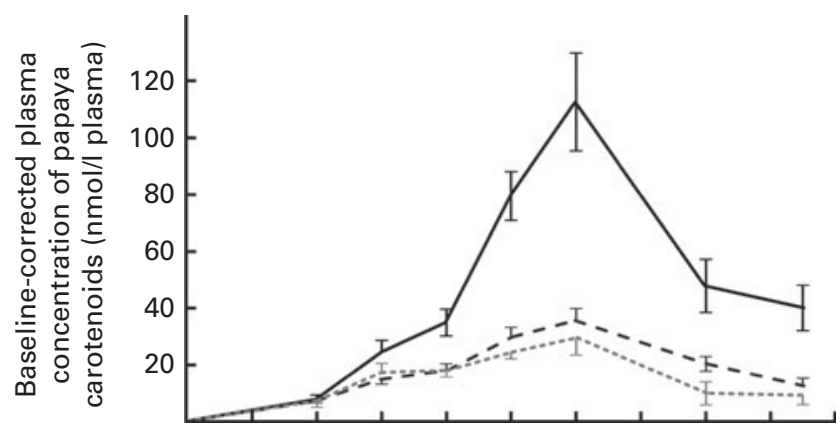

(b)

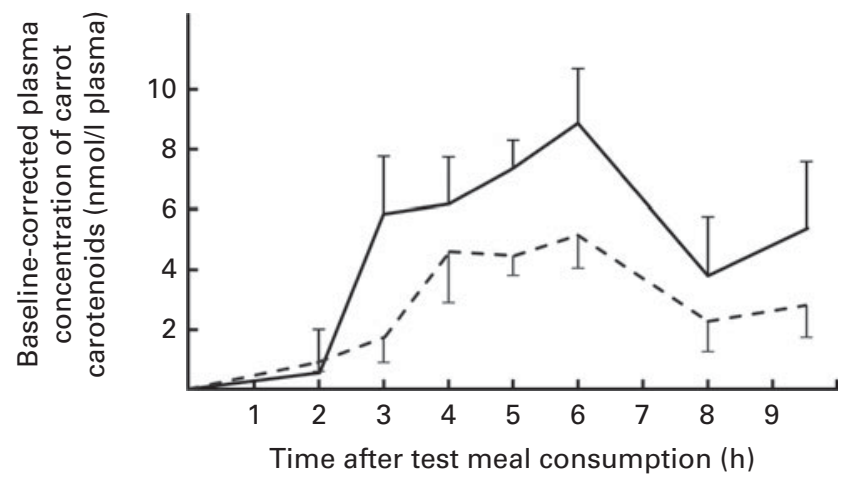

Fig. 2. Baseline-corrected plasma TAG-rich lipoprotein concentrations of carotenoids over $9.5 \mathrm{~h}$ after the consumption of the (a) papaya test meal and (b) the carrot test meal. Values are means ( $n$ 16), with their standard errors represented by vertical bars. Mean value of $\beta$-cryptoxanthin (-) was significantly higher than that of lycopene $(--)$ or $\beta$-carotene $(-.$. $(P \leq 0.001)$. (b) - $\beta$-Carotene; --, $\alpha$-carotene.

after the intake of the papaya test meal (Fig. 2(a)). The $6 \mathrm{~h}$ peak concentration of $\alpha$-carotene after the consumption of the carrot test meal was $5 \cdot 1$ (sem 1.1) nmol/l plasma (Fig. 2(b)).

Major carry-over, period and time effects on carotenoid absorption were not observed. In addition, a significant correlation of participants' age, BMI or sex with carotenoid absorption was not found. However, it should be noted that investigating such effects was not the goal of the present study.

\section{Discussion}

\section{Absorption of carotenoids from papayas,} tomatoes and carrots

The release of ingested carotenoids from the food matrix and their subsequent incorporation into mixed micelles during digestion are prerequisites for their efficient absorption ${ }^{(4)}$. Many factors influence this process as discussed below, based on the observations made in the present study.

The influence of the carotenoid species and the total carotenoid dose on bioavailability has been reported previously, since interactions of carotenoids may lead to competition for absorption ${ }^{(8,9)}$. For instance, the xanthophyll lutein has been shown to have a negative effect on the absorption of $\beta$-carotene and vice versa ${ }^{(7)}$. In the present study, in the papaya test meal, $\beta$-carotene and lycopene were present along with the free and esterified xanthophyll $\beta$-cryptoxanthin, whereas in the carrot and tomato test meals, only other carotenes such as $\alpha$-carotene, $\beta$-carotene and lycopene were present at relevant concentrations (Table 1). Also, the papaya test meal contained slightly more total carotenoids (approximately 16.4 mg) than the tomato test meal (15.3 mg) and considerably more than the carrot test meal (approximately $2.3 \mathrm{mg}$ ). Although the papaya test meal contained the highest amount of accompanying carotenoids, possibly competing with $\beta$-carotene and lycopene for absorption, $\beta$-carotene and lycopene were more bioavailable from the papaya test meal than from the other test meals.

Pectin and other dietary fibres have been reported to have a negative impact on the bioavailability of carotenoids ${ }^{(11,12)}$. According to the USDA Nutrient Database ${ }^{(19)}$, the estimated total amounts of dietary fibre in the test meals were $6.8-8.6 \mathrm{~g}$ (papaya), 3.1-4.8g (tomato) and 0.7-1.0 g (carrot). Although the papaya test meal contained substantially more dietary fibre, lycopene and $\beta$-carotene were more bioavailable from the papaya test meal than from the tomato and carrot test meals. Thus, other factors that increased the bioavailability of carotenoids must have surpassed any adverse impact that dietary fibre may have had on the release and absorption of carotenoids in the present study.

Important factors reducing the bioavailability of carotenoids from the carrot test meal may be the firmer texture and the smaller meal size when compared with the papaya and tomato test meals. For raw carrots, Lemmens et al. ${ }^{(26)}$ showed a strong positive correlation of particle size reduction, i.e. more intense mastication, with enhanced bioaccessibility of carotenoids in vitro. After rigorous cooking of the carrots, the specific dependency of the bioaccessibility of $\beta$-carotene on the particle size of the carrot tissue disappeared. The softer tissue of the cooked carrots can be ruptured more easily by the motile gastrointestinal tract, whereas raw carrots require more extensive mastication or other pretreatments ${ }^{(26)}$. By analogy, carotenoids might have been released more easily from the softer papaya tissue than from the carrot tissue, although the participants of the present study were instructed to chew their test foods well ( $\geq 15$ times). However, this hypothesis does not explain the strong differences in the bioavailability of carotenoids from papayas and tomatoes, the tissues of which were of comparable firmness. Furthermore, the differences in the absorption of $\beta$-carotene from tomatoes and carrots were insignificant $(P>0.863)$, although the firmness of these plant tissues was different.

Read et al. ${ }^{(27)}$ described longer transit times for larger meals. Although little is known about the relationship between carotenoid absorption and meal transit time in the gastrointestinal tract, Faulks et $a l{ }^{(28)}$ reported more efficient absorption of lutein from spinach along with increasing transit time. At the same time, $\beta$-carotene absorption was not affected in their study. The present results suggest that different transit times had little impact on the bioavailability of carotenoids, as the absorption of $\beta$-carotene from the comparatively large tomato test meal and the small carrot meal was similar.

A comprehensive explanation for the high bioavailability of carotenoids from papaya fruits can be derived from their 
chromoplastidal deposition form, i.e. their physical state in the plant's chromoplast ${ }^{(13)}$. In carrots and tomatoes, $\beta$-carotene is deposited in large crystalloid chromoplasts. In papayas, lipid-dissolved and liquid-crystalline $\beta$-carotene and free and esterified $\beta$-cryptoxanthin are found in nano-substructures of a globular-tubular shape. These globules and tubules are small in size, and the physical state of $\beta$-carotene in papayas is lipid dissolved and liquid crystalline in nature ${ }^{(13)}$. Taken together, these differences could be hypothesised to increase the bioavailability of $\beta$-carotene from papayas compared with tomatoes or carrots. Following this argument, no difference in the bioavailability of $\beta$-carotene should be observed between tomatoes and carrots. In fact, we observed that carotenoid absorption was higher for papayas than for carrots and tomatoes, but not significantly different between tomatoes and carrots, both of which contain crystalloid accumulations of $\beta$-carotene. This result supports the hypothesis that the chromoplastidal deposition of carotenoids directly affects their bioavailability.

Regarding the bioavailability of lycopene, both tomatoes and papayas contain solid-crystalline accumulations of this carotenoid within their chromoplasts. However, the size of the crystalloid chromoplasts has been shown to be significantly smaller in papayas than in tomatoes ${ }^{(13)}$. In general, the dissolution rate of crystals strongly depends on their particle size ${ }^{(29)}$. This relationship has been used previously to enhance the oral bioavailability of hydrophobic drugs ${ }^{(30)}$. Thus, small lycopene crystals from papayas may exhibit a higher bioavailability than the larger lycopene crystals from tomatoes. Moreover, lycopene crystals in papayas have been found to be located in a peripheral, nutshell-like position in the chromoplasts, which may also contribute to a preferable surface:volume ratio for dissolution in dietary lipids ${ }^{(13)}$.

As has been outlined above, carotenoid absorption may be influenced by a large variety of factors. However, the primary differences in bioavailability observed after the consumption of the test meals in the present study could most comprehensively be explained by the morphologically and physically different substructures of chromoplasts. Globular-tubular chromoplasts with lipid-dissolved and liquid-crystalline carotenoids have been identified previously in other fruits and vegetables, for example, in mangos and red peppers ${ }^{(16,31)}$. The bioaccessibility of $\beta$-carotene from mangoes, i.e. its release and micellisation during simulated in vitro digestion, has recently been shown to be significantly higher than that from carrots and tomatoes ${ }^{(17)}$, further supporting our hypothesis. An overview of the morphology of chromoplasts in different fruits, vegetables and other plant tissues has been presented by Sitte et al. ${ }^{(32)}$.

\section{Retinyl esters in the TAG-rich lipoprotein fractions after test meal consumption}

Fig. 1(c) shows the appearance of retinyl esters in the TRL fractions after the ingestion of the test meals. The present study demonstrated that the consumption of the papaya test meal led to a significant postprandial rise in the concentrations of retinyl esters in the TRL fractions. Although the AUC for retinyl esters in the papaya test meal was 2.0 and 2.6 times higher than that in the tomato and carrot test meals, respectively ( $P \leq 0.0002$ and $P \leq 0.0014$, respectively), comparison of these curves is difficult. The test meals contained variable amounts of provitamin A carotenoids, expressed as retinol activity equivalents in Table 1 . The similarity between the concentrations of provitamin $\mathrm{A}$ in the test foods may be deceiving, since in the calculation of retinol activity equivalents based on the guidelines of the US Institute of Medicine ${ }^{(33)}$, generalised factors for release and absorption are used without offering modification factors for specific food matrices. The present study clearly shows that the food matrix has a crucial impact on the bioavailability of both provitamin A and non-provitamin A carotenoids. Hence, the calculation of retinol activity equivalents should be used as a rough estimation for non-green fruits and vegetables and not specifically for comparing different food matrices.

\section{Absorption of $\alpha$-carotene from carrots and $\beta$-cryptoxanthin from papayas}

The absorption of $\alpha$-carotene from carrots and $\beta$-cryptoxanthin from papayas was monitored due to their nutritional importance as provitamin A carotenoids. Considering only the absorption of carotenoids from carrots, the AUC for $\alpha$-carotene was about $56 \%$ of that for $\beta$-carotene (Fig. 2(b)). Hence, significantly more $\beta$-carotene than $\alpha$-carotene was absorbed from the carrot test meal ( $P \leq 0 \cdot 0029)$. Nevertheless, since the $\alpha$-carotene dose $(0.74 \mathrm{mg})$ was also approximately half as high (approximately $46 \%$ ) as the $\beta$-carotene dose $(1.60 \mathrm{mg})$, the bioavailability of both carotenes from the carrot test meal seemed to be similar.

The present study shows that a single dose of $2.1 \mathrm{mg}$ $\beta$-cryptoxanthin from fresh, unprocessed papaya is highly bioavailable in humans. The bioavailability of $\beta$-cryptoxanthin was apparently 2.9 and 2.3 times higher than that of $\beta$-carotene and lycopene from papayas $(P \leq 0.0001$ and $P \leq 0.0003$, respectively, see Fig. 2(a)). Comparing the mean dietary intake and mean blood levels of $\beta$-carotene and $\beta$-cryptoxanthin, Burri et al. ${ }^{(34)}$ had previously hypothesised that the higher bioavailability of $\beta$-cryptoxanthin is due to its lower intake but comparatively high blood levels. Some xanthophylls have been shown to have high bioavailability previously. For example, lutein has been shown to be five times more bioavailable than $\beta$-carotene from vegetables $^{(6)}$. In good agreement with the present results, Borel et $a l^{(35)}$ demonstrated that the hydrophobicity of lipophilic compounds was inversely related to the extent of incorporation into mixed micelles. The hydroxyl function of $\beta$-cryptoxanthin may enable efficient micellarisation, which may ultimately lead to enhanced bioavailability. By analogy, $\beta$-cryptoxanthin in citrus juices has been shown to be highly bioavailable for absorption by Caco-2 cells ${ }^{(36)}$ and, furthermore, $\beta$-cryptoxanthin has been reported to be more bioavailable in Mongolian gerbils ${ }^{(37)}$.

The higher bioavailability of the provitamin A carotenoid $\beta$-cryptoxanthin could have practical consequences on vitamin A status. Although $\beta$-cryptoxanthin theoretically 
possesses only half of the vitamin A activity of $\beta$-carotene, the 3 -fold higher bioavailability of $\beta$-cryptoxanthin observed in the present study could offset this disadvantage. Since papaya is commonly consumed in many tropical and subtropical countries where vitamin A deficiencies are observed ${ }^{(1)}$, this fruit offers a potential source of provitamin A to these populations. Besides its provitamin A activity, $\beta$-cryptoxanthin has also been associated with other health benefits, e.g. increased bone health ${ }^{(38-40)}$.

\section{Conclusions}

In the present study, $\beta$-carotene was approximately three times more bioavailable from fresh red-fleshed papaya fruits than from carrots and tomatoes $(P \leq 0 \cdot 001)$, whereas differences in the bioavailability of $\beta$-carotene from carrots and tomatoes were insignificant $(P>0.863)$. At the same time, higher concentrations of vitamin A, i.e. retinyl esters, were also observed after the consumption of the papaya test meal. The bioavailability of lycopene from papayas was approximately 2.6 times higher than that from tomatoes $(P \leq 0.001)$. On comparing only papaya carotenoids, the bioavailability of $\beta$-cryptoxanthin was observed to be 2.9 and $2 \cdot 3$ times higher than that of $\beta$-carotene and lycopene, respectively $(P \leq 0 \cdot 0003)$.

In conclusion, raw red-fleshed papayas provide a more bioavailable source of lycopene and $\beta$-carotene when compared with raw tomatoes and raw carrots, respectively. Our observations suggest that the different deposition forms of carotenoids in the respective chromoplasts might be a decisive factor influencing the bioavailability of carotenoids from the fresh, non-processed, non-green fruits and vegetables. The provitamin A carotenoid $\beta$-cryptoxanthin was also shown to be highly bioavailable from papayas and high concentrations of retinyl esters (i.e. vitamin A) were observed in TRL fractions after the consumption of the papaya test meal. Thus, papaya represents a valuable source of lycopene and provitamin A carotenoids, and its use for reducing the incidence of vitamin A deficiencies in developing countries is recommended.

\section{Acknowledgements}

The authors gratefully acknowledge the technical assistance of Ana Lorena Torres during the clinical trial. The present study was supported by the German Academic Exchange Service (DAAD scholarship to R. M. S.). The DAAD had no role in the design and analysis of the study or in the writing of this article.

The authors' responsibilities are as follows: R. M. S., S. Q., P. E., S. J. S. and R. C. designed the research; R. M. S., R. E. K., M. G. V.-G., S. Q. and P. E. conducted the research; M. G. V.-G. and P. E. enrolled the participants; R. M. S. and R. E. K. analysed the data; J. H. and R. M. S. carried out the statistical analyses; R. M. S. wrote the manuscript and designed the figures/tables; R. E. K., S. J. S. and R. C. revised the manuscript and contributed substantially to the discussion. All authors read and approved the final manuscript.

None of the authors has any conflicts of interest to declare.

\section{References}

1. WHO (2009) Global prevalence of vitamin A deficiency in populations at risk 1995-2005. WHO Global Database on Vitamin A Deficiency 1-19.

2. Böhm V (2012) Lycopene and heart health. Mol Nutr Food Res 56, 296-303.

3. Harrison EH (2012) Mechanisms involved in the intestinal absorption of dietary vitamin A and provitamin A carotenoids. Biochim Biophys Acta 1821, 70-77.

4. Borel P (2003) Factors affecting intestinal absorption of highly lipophilic food microconstituents (fat-soluble vitamins, carotenoids and phytosterols). Clin Chem Lab Med 41, 979-994.

5. Castenmiller JJM \& West CE (1998) Bioavailability and bioconversion of carotenoids. Annu Rev Nutr 18, 19-38.

6. Van Het Hof KH, Brouwer IA, West CE, et al. (1999) Bioavailability of lutein from vegetables is 5 times higher than that of b-carotene. Am J Clin Nutr 70, 261-268.

7. Kostic D, White WS \& Olson JA (1995) Intestinal absorption, serum clearance, and interactions between lutein and $\beta$-carotene when administered to human adults in separate or combined oral doses. Am J Clin Nutr 62, 604-610.

8. van het Hof KH, West CE, Weststrate JA, et al. (2000) Dietary factors that affect the bioavailability of carotenoids. $J$ Nutr 130, 503-506.

9. Tyssandier V, Cardinault N, Caris-Veyrat C, et al. (2002) Vegetable-borne lutein, lycopene, and $\beta$-carotene compete for incorporation into chylomicrons, with no adverse effect on the medium-term (3-wk) plasma status of carotenoids in humans. Am J Clin Nutr 75, 526-534.

10. Brown MJ, Ferruzzi MG, Nguyen ML, et al. (2004) Carotenoid bioavailability is higher from salads ingested with full-fat than with fat-reduced salad dressings as measured with electrochemical detection. Am J Clin Nutr 80, 396-403.

11. Riedl J, Linseisen J, Hoffmann J, et al. (1999) Some dietary fibers reduce the absorption of carotenoids in women. J Nutr 129, 2170-2176.

12. Rock CL \& Swendseid ME (1992) Plasma $\beta$-carotene response in humans after meals supplemented with dietary pectin. Am J Clin Nutr 55, 96-99.

13. Schweiggert RM, Steingass CB, Heller A, et al. (2011) Characterization of chromoplasts and carotenoids of red and yellow fleshed papaya (Carica papaya L.). Planta 234, 1031-1044.

14. Britton G (2008) Functions of intact carotenoids. In Carotenoids Volume 4: Natural Functions, pp. 189-236 [G Britton, S Liaaen-Jensen and H Pfander, editors]. Basel: Birkhäuser Verlag.

15. Rock CL, Lovalvo JL, Emenhiser C, et al. (1998) Bioavailability of $\beta$-carotene is lower in raw than in processed carrots and spinach in women. J Nutr 128, 913-916.

16. Vásquez-Caicedo AL, Heller A, Neidhart S, et al. (2006) Chromoplast morphology and $\beta$-carotene accumulation during postharvest ripening of mango cv. 'Tommy Atkins'. J Agric Food Chem 54, 5769-5776.

17. Schweiggert RM, Mezger D, Schimpf F, et al. (2012) Influence of chromoplast morphology on carotenoid bioaccessibility of carrot, mango, papaya, and tomato. Food Chem 60 , $2577-2585$.

18. Schweiggert RM, Steingass CB, Esquivel P, et al. (2012) Chemical and morphological characterization of Costa Rican papaya (Carica papaya L.) hybrids and lines with particular focus on their genuine carotenoid profiles. J Agric Food Chem 60, 2577-2585.

19. US Department of Agriculture (2011) Nutrient data laboratory home page. USDA National Nutrient Database 
for Standard Reference Release 24. http://www.ars.usda. gov/ba/bhnrc/ndl (accessed July 2011)

20. Terpstra AHM (1985) Isolation of serum chylomicrons prior to density gradient ultracentrifugation of other serum lipoprotein classes. Anal Biochem 150, 221-227.

21. O'Neill ME \& Thurnham DI (1998) Intestinal absorption of $\beta$-carotene, lycopene and lutein in men and women following a standard meal: response curves in the triacylglycerol-rich lipoprotein fraction. Br J Nutr 79, 149-159.

22. Schweiggert RM, Steingass CB, Mora E, et al. (2011) Carotenogenesis and physico-chemical characteristics during maturation of red fleshed papaya fruit (Carica papaya L.). Food Res Int 44, 1373-1380.

23. Kopec RE, Schweiggert RM, Riedl K, et al. (2012) Comparison of HPLC-MS/MS and HPLC-DAD for the quantitation of carotenoids, retinyl esters, $\alpha$-tocopherol, and phylloquinone in chylomicron-rich fractions of human plasma. Rapid Commun Mass Spectrom 27, 1393-1402.

24. Britton G (1995) UV/visible spectroscopy. In Carotenoids Volume 1B: Spectroscopy, pp. 13-62 [G Britton, S LiaaenJensen and $\mathrm{H}$ Pfander, editors]. Basel/Boston/Berlin: Birkhäuser Verlag.

25. Unlu NZ, Bohn T, Clinton SK, et al. (2005) Carotenoid absorption from salad and salsa by humans is enhanced by the addition of avocado or avocado oil. J Nutr 135, 431-436.

26. Lemmens L, Van Buggenhout S, Van Loey AM, et al. (2010) Particle size reduction leading to cell wall rupture is more important for the $\beta$-carotene bioaccessibility of raw compared to thermally processed carrots. J Agric Food Chem 58, 12769-12776.

27. Read NW, Cammack J \& Edwards C (1982) Is the transit time of a meal through the small intestine related to the rate at which it leaves the stomach? Gut 23, 824-828.

28. Faulks RM, Hart DJ, Brett GM, et al. (2004) Kinetics of gastrointestinal transit and carotenoid absorption and disposal in ileostomy volunteers fed spinach meals. Eur J Nutr 43, $15-22$.

29. Tang R, Orme CA \& Nancollas GH (2004) Dissolution of crystallites: surface energetic control and size effects. ChemPhysChem 5, 688-696.

30. Liversidge GG \& Cundy KC (1995) Particle size reduction for improvement of oral bioavailability of hydrophobic drugs:
I. Absolute oral bioavailability of nanocrystalline danazol in beagle dogs. Int J Pharm 125, 91-97.

31. Frey-Wyssling A \& Kreutzer E (1958) The submicroscopic development of chromoplasts in the fruit of Capsicum annuum L. J Ultrastruct Res 1, 397-411.

32. Sitte P, Falk H \& Liedvogel B (1980) Chromoplasts. In Pigments in Plants, pp. 117-148 [F Czygan, editor]. Stuttgart: $G$ Fischer.

33. Institute of Medicine (2001) Vitamin A. Dietary Reference Intakes for Vitamin A, Vitamin K, Arsenic, Boron, Chromium, Copper, Iodine, Iron, Manganese, Molybdenum, Nickel, Silicon, Vanadium, and Zinc, pp. 82-161, [Institute of Medicine, Food and Nutrition Board, editor]. Washington, DC: National Academic Press.

34. Burri BJ, Chang JST \& Neidlinger TR (2011) $\beta$-Cryptoxanthinand $\alpha$-carotene-rich foods have greater apparent bioavailability than $\beta$-carotene-rich foods in Western diets. $\mathrm{Br} \mathrm{J}$ Nutr 105, 212-219.

35. Borel P, Grolier P, Armand M, et al. (1996) Carotenoids in biological emulsions: solubility, surface-to-core distribution, and release from lipid droplets. J Lipid Res 37, 250-261.

36. Dhuique-Mayer C, Borel P, Reboul E, et al. (2007) $\beta$-Cryptoxanthin from citrus juices: assessment of bioaccessibility using an in vitro digestion/Caco-2 cell culture model. Br J Nutr $\mathbf{9 7}$, 883-890.

37. Davis C, Jing H, Howe JA, et al. (2008) $\beta$-Cryptoxanthin from supplements or carotenoid-enhanced maize maintains liver vitamin A in Mongolian gerbils (Meriones unguiculatus) better than or equal to $\beta$-carotene supplements. Br J Nutr 100, 786-793.

38. De Roos AJ, Arab L, Renner JB, et al. (2001) Serum carotenoids and radiographic knee osteoarthritis: the Johnston County Osteoarthritis Project. Public Health Nutr 4, 935-942.

39. Cerhan JR, Saag KG, Merlino LA, et al. (2003) Antioxidant micronutrients and risk of rheumatoid arthritis in a cohort of older women. Am J Epidemiol 157, 345-354.

40. Maggio D, Polidori MC, Barabani M, et al. (2006) Low levels of carotenoids and retinol in involutional osteoporosis. Bone 38, 244-248. 